$\underline{\mathbf{P}-136}$

\title{
Post Harvest Handling, Formulation and Evaluationof Semisolid jelly Produced by Local Dream Banana Peel
}

\author{
Azwani, M.R ${ }^{1, *}$, Nordin, M.F.M ${ }^{1}$ and Norazah, A.R ${ }^{2}$ \\ ${ }^{1}$ Universiti Malaysia Kelantan, Faculty of Agro Based Industry, Jeli Campus, Locked beg 100, 17600, Jeli, Kelantan, \\ Malaysia; ${ }^{2}$ Universiti Teknologi Mara, Faculty of Chemical Engineering, Universiti Teknologi Mara, 40450 Shah Alam, \\ Selangor, Malaysia; E-mail: inawza_80@yahoo.com
}

The origin of local Dream bananas were consisted in post harvest data which analyzed for preliminary studies with regards to the parameters peel colour index, stage and periods of ripening, ripening storage, and quality appearances. Furthermore, the objectives of this study were conducted with a view to formulate and evaluate the unit of nutritional jelly. The investigation of pectin extracts from banana is estimated amount of pectin contents about $40.56 \%$. Thus, higher pectin content may help the jelly set up without added any pectin and formulated using factorial design, amount of sugar and citric acid. All the fourteen formulation (F1-F14) under study was found to be stable and showed comparable appearance, PH and TSS. According to statistical optimization within targeted response TSS at $72{ }^{\circ} \mathrm{Brix}$ and $\mathrm{PH}$ at 3.3, the global solution noted amount of sugar is $19.03 \mathrm{~g}$ and citric acid is $0.208 \mathrm{~g}$. The optimized amount of ingredients are consider for jelly replicates (J1, J2, J3, J4, J5, J6) and the stability of jelly was carried out in appearance, storage temperature, $\mathrm{PH}$, viscosity and sugar crystallization. During 60 days stability evaluation, the $\mathrm{PH}$ and viscosity of $\mathrm{J} 1, \mathrm{~J} 3$ and $\mathrm{J} 5$ batches jelly is not well affected at room temperature. Otherwise the appearance of $\mathrm{J} 2, \mathrm{~J} 4$ and $\mathrm{J} 6$ are affected due to colour changes at $4^{\circ} \mathrm{C}$ condition. 